This is the accepted manuscript of the article, which has been published in Nordic Journal of Psychiatry. 2019. https://doi.org/10.1080/08039488.2019.1667429

\title{
Time trends in referrals to child and adolescent gender identity services: A study in four Nordic countries and in the UK
}

Riittakerttu Kaltiala, Tampere University, Faculty of Medicine and Life Sciences, and Tampere University Hospital, Department of Adolescent Psychiatry, Box 2000, 33521 Tampere, Finland

Hannah Bergman, MSc, Karolinska Institutet, Stockholm, Sweden

Polly Carmichael, PhD., Gender identity Development Service, Tavistock and Portman NHS Foundation Trust, 120 Belsize Lane, NW3 5BA, London, UK.

Nastasja M. de Graaf, MSc., Gender identity Development Service, Tavistock and Portman NHS Foundation Trust, 120 Belsize Lane, NW3 5BA, London, UK.

Karen Egebjerg Rischel, MD, Sexological Clinic, Psychiatric Centre Copenhagen, Blegdamsvej 9, 2100 Copenhagen, Denmark.

Louise Frisén, MD, PhD, Department of Clinical Neuroscience, Karolinska Institutet, Stockholm, Sweden

Martina Schorkopf, MD, Gender Identity Clinic for Children, Department of Child and Adolescent Psychiatry, Division of Paediatric and Adolescent Medicine, Oslo University Hospital, Box 4950 Nydalen, 0424 Oslo Norway.

Laura Suomalainen, MD, PhD, Helsinki University Hospital, Department of Adolescent Psychiatry Anne Wæhre, MD, PhD, Gender Identity Clinic for Children, Department of Child and Adolescent Psychiatry, Division of Paediatric and Adolescent Medicine, Oslo University Hospital, Box 4950 Nydalen, 0424 Oslo, Norway. 
Acknowledgements:

Thanks to Birte Smidt, MD, Head of Outpatient Clinics, Psychiatric Centre Copenhagen, for her assistance in providing the data for Denmark. 


\begin{abstract}
Purpose: To explore whether the increase observed in referrals to child and adolescent gender identity services (GIDS) has been similar in four Nordic countries and in the UK.

Materials and methods: Numbers of referrals per year in 2011-2017 were obtained from all GIDS in Denmark, Finland, Norway, Sweden and the UK and related to population aged $<18$.

Results: A similar pattern of increase in referral rates was observed across countries, resulting in comparable population adjusted rates in 2017. In children, male:female birth sex ratio was even; in adolescents a preponderance of females (birth sex) was observed, particularly in Finland.

Conclusion: The demand for gender identity services has evolved similarly across Nordic countries and the UK. The reasons for the increase are not known but increased awareness of gender identity issues, service availability, destigmatization as well as social and media influences may play a role.
\end{abstract}

Keywords: Gender identity, time trends, referral rates, children and adolescents 


\section{Introduction}

Gender Dysphoria in DSM-5 (1) refers to a condition in which an individual senses a marked discrepancy between her/his experienced gender and her/his sex, and this causes clinically significant distress or impairment in important areas of functioning. Most individuals with Gender Dysphoria have a strong desire to be treated as the opposite gender (or some alternative gender) and/or to be rid of their natal sexual characteristics and a strong conviction of having feelings and reactions typical of the other gender (or some alternative gender). ICD-10 and ICD-11 respectively refer to the discrepancy between biological sex and experienced gender by Transsexualism and Gender Incongruence $(2,3,4)$. The term "transgender" refers to a variety of gender identities incongruent with one's biological sex $(5,6)$, whereas cisgender refers to individuals whose gender identity congruent with their birth sex (7). Not all those identifying as transgender necessarily suffer from dysphoria.

Healthy children vary considerably in gender expression (8). Of children with even a marked incongruence between their sex and experienced gender, about four out of five are known to develop towards identifying with their biological sex at puberty (9). Therefore, medical treatments modifying sexual characteristics are not recommended before puberty. In some children displaying gender incongruence gender dysphoria intensifies at puberty. Adolescents with gender dysphoria may benefit from psychotherapeutic work in order to explore gender identity, alleviate distress and tackle psychosocial problems and comorbid disorders, but they may also wish and be eligible to proceed to medical interventions aiming at aligning the bodily characteristics with perceived gender $(9,10,11)$. Currently, according to the so-called Dutch model of care, the development of secondary sexual characteristics can be halted from the early stages (Tanner II-III) of puberty by applying gonadotropin-releasing hormone ( $\mathrm{GnRH}$ ) analogues, and cross-sex hormonal treatments initiated from about age 16 . Surgical treatments are mainly available for legal adults $(10,11)$. GnRH analogues ("puberty blockers") from the early stages of puberty prevent the development of secondary sex characteristics. On the one hand this may reduce anxiety, and later cross-sex hormone treatment may also result in more satisfactory outcome (10). On the other hand, it may also create new challenges for medical sex reassignment. Male to female genital surgery, for example, is more complicated if the penis has remained very small (12). The impact of puberty blocking on the developing brain is further not completely known $(13,14)$, nor are the effects on bone mineral density $(15,16)$. Transgender adolescents may want to preserve fertility, which may be compromised if puberty is suppressed at an early stage (17). Increased in fat mass has been observed in gender incongruent adolescents treated with GnRH analogues (18). Cost-effectiveness of gender reassignment treatments of minors has not been studied.

The number of adolescents contacting specialized gender identity services has risen considerably over the past decade throughout Europe and North America $(19,20,21,22,23)$. At the same time, the preponderance of natal boys identifying as girls, seen earlier among gender-referred minors - particularly in prepubertal children - has changed to a more equal male:female ratio, or indeed to a preponderance of natal females, particularly among adolescents $(19,20,22,24)$. The reasons for these rapid new developments are not known (25).

In Denmark, Finland, Norway, Sweden and the UK, publicly funded, nationally centralized gender identity services are available for minors under 18 years. In the UK, a child and adolescent gender identity development service has been in operation in Tavistock Clinic, London, since 1989. The GIDS has several satellite clinics across the UK, in Leeds (North) and Exeter (South), and provides consultation across the country (including Wales, Midlands and Ireland). A vast increase in referrals has been observed throughout the 2000's. In the Nordic countries a gender identity service for minors was first established in Sweden in Stockholm in the 1990's. This became a part of public child and adolescent healthcare in 2014. Due to increased demand, several other gender identity services in the country also nowadays accept referrals of minors. In Finland gender identity services for minors were opened in Tampere and Helsinki University 
hospitals in 2011. In Norway a national gender identity service in Oslo was always open to minors but before the 2000's rarely received referrals concerning children and adolescents. In Denmark a gender identity service for minors was established in Copenhagen in 2016. These services are responsible for the diagnostic evaluation of gender identity development and eligibility for medical gender identity-based interventions, taking into account mental health problems and associated needs.

The clinical impression is that in numbers of minors seeking gender identity services, remarkable increases have taken place at about the same time in different countries, and an increasingly uneven sex ratio is emerging. The aim of this study is to explore trends in referrals to child and adolescent gender identity services in the Nordic countries and compare them with those in the UK, where services have been available for a longer time. In more detail we aim to explore

1. How have numbers of referrals evolved over time during the 2000's in Denmark, Finland, Norway, Sweden and the UK?

2. What are the population adjusted rates of minors seeking gender identity services in these countries?

3. How has sex ratio developed among those referred to gender identity services for minors since 2010 ?

\section{Materials and methods}

Statistics concerning number of referrals per year, and proportions of girls and boys (by birth sex) among children and adolescents referred were collected from the child and adolescent gender identity services in Denmark, Finland, Norway, Sweden and the UK. Population based figures were calculated based on the most recent population census (0-17-year-olds) in each country $(26,27,28,29,30)$.

\section{Data analyses}

The study comprises descriptive analyses. Absolute numbers of referrals per year since 2010 are presented for each country. Proportions per 100,000 minors are calculated and compared using cross-tabulations with chi-square statistics. Birth sex ratio (female:male) is given for total samples and stratified for age group (children 0-12 years, adolescents 13-17 years) and compared using cross-tabulations with chi-square statistics/ Fisher's exact test where appropriate.

\section{Results}

The number of referrals has increased throughout the 2010's in Finland, Norway, Sweden and the UK. In Denmark, where the opening of a gender identity service for minors is the most recent, the number of referrals was at once closer to the latest developments in the other Nordic countries than to the situation in the other Nordic countries at the beginning of the period studied. (Figures 1 and 2)

(Insert Figures 1 and 2 about here)

Population adjusted figures in 2011 were higher in Finland than in Norway, Sweden and the UK. In the latter three countries, the figures were comparable. In 2017 the population adjusted figures were close to 
each other in Finland, Norway, Sweden and the UK and somewhat lower in Denmark, where the service had just been opened in 2016 (Table 2).

(Insert Table 2 about here)

An increase in female:male ratio among those referred to the child and adolescent gender identity services was seen across the countries from 2010 to 2017. Finland was distinguished with a higher female:male ratio among the gender-referred minors than in the other countries studied. (Figure 3 ) Among children there seemed to be relatively more boys in Finland (female:male ratio 0.3) and the UK (0.6), and an even sex distribution was seen in Denmark (1.1), Norway (1.0) and Sweden (1.0), but none of the pairwise differences was statistically significant. Among adolescents there was a preponderance of females with female:male ratios of 4.1 in Denmark, 7.1 in Finland, 1.7 in Norway, 3.2 in Sweden and 2.5 in the UK. (Pairwise differences between countries were statistically significant at level $p<0.001$ except Sweden vs. UK and Denmark vs Sweden at level $p<0.05)$.

(Inset Figure 3 about here)

\section{Discussion}

An increase in referrals to child and adolescent gender identity services was seen during the 2010's in the four Nordic countries studied and in the UK. The increase occurred at the same time in both countries where the service had been available for a longer time (Norway, Sweden the UK) and in those which established services specifically for minors during the 2010's (Denmark, Finland). What is more, the population adjusted figures were both much higher than what has been previously reported for adults (5), and the latest observations were on a strikingly similar level in the countries studied with the exception that in Denmark, where the service was very recent, figures were somewhat lower.

The sudden increase in the demand for health services could be due, for example, to an increase in the prevalence of the health problem concerned, increased awareness of treatment needs and options, better availability of services, decreased stigma or similar psychosocial obstacles, or lowered threshold to obtaining treatment. Interestingly, a recently published article on Stockholm shows a reported wish for gender affirming medical treatment in $0.5 \%$ of the general population of Stockholm. These findings greatly exceed estimates of the number of patients receiving gender-affirming medical care and could may suggest that far more people than previously thought would like gender-affirming medical interventions (31). Transgender identity experiences among adolescent population still appear to be far more common (32)

The aetiology of transsexualism is unknown (33). Aetiological factors for gender identity incongruent with sex have been sought in biological, psychological and sociocultural factors $(33,34,35 \mathrm{U})$, with inconclusive results. Therefore, the impact of possible changes in factors contributing to gender dysphoria on increasing demand on services cannot be assessed. The gender identity discussion further nowadays increasingly involves non-binary and fluid gender identities, which likely means that multifactorial developments are in question. Nevertheless, rapid changes in any relevant biological factor in populations are unlikely.

With widely increased media coverage of transgender issues in all the countries studied, awareness of gender identity issues and treatment options have likely increased. In Denmark and Finland gender identity services were not available to minors before the 2010's. The very opening of the services was certainly related to increasing pressures from international discussions around gender identity issues. Awareness of 
treatment options and availability of services develop in complex interplay with each other. Increased awareness and service availability may have a role in the developments observed in the present study. In the UK, the GIDS was nationally commissioned in 2009, and particular effort was made to improve awareness and acceptance of gender diversity and sex reassignment.

Among children and adolescents social discrimination and peer rejection are commonly discussed as a particular problem related to gender identity and gender expression incongruent with one's sex $(36,37)$, and minors in contact with gender identity services have reported experiences of subjection to bullying and other peer difficulties as commonly as those referred due to mental health issue, and much more commonly than children and adolescents at large $(38,39,40,41,42)$. However, experiences of bullying may also precede the onset of gender dysphoria (40), and recent studies have also paid attention to ample social support and peer acceptance following disclosure of other than cisgender gender identity among young people $(34,35)$. Both stigma and improved inclusion / sense of belonging are likely factors relevant for gender identity development in minors. Reduced stigma and improved social support may have a role in the developments observed in the present study.

Both the diagnostic classifications widely used in psychiatry in Western countries, the DSM by the American Psychiatric Association and the ICD by WHO have during the 2010's broadened the definitions of conditions related to gender identity. Broadening the diagnostic definitions likely results in more people fulfilling the criteria and being considered eligible for medical interventions, which may have a role in the developments observed in the present study.

The population adjusted rates clearly higher than those seen among adults (5) may suggest that gender dysphoria is becoming increasingly common in younger age cohorts. However, methodologically sound epidemiological studies that could verify this are not available. Identity development is a central developmental task of adolescence that takes place through identity explorations and choices that finally converge towards identity achievement $(43,44,45)$. A share of adolescent non-cisgender identity experiences may be a part of normative identity exploration. It is important that adolescents can explore identity options and express themselves freely, but hasty medical interventions may not always be advisable. Psychotherapy may facilitate identity exploration (11).

The reasons for the prepoderance of birth assigned girls among adolescents seeking gender identity based medical interventions documented in the present study in the Nordic countries, and also earlier in Europe and North America $(19,20)$, are not known. Particularly the seven-fold preponderance of females over males in adolescents seeking gender reassignment in Finland remains unexplained. The Nordic countries all rank high in gender equality (46). Thus, gender roles may be less dichotomized than elsewhere, possibly allowing young females more room to express themselves freely as regards behaviours considered genderatypical. Masculinity in girls may further be increasingly accepted, in contrast to femininity in boys (9). Gender equality broadening the options for women in all domains of life could give girls more freedom to explore masculine identities and seek for gender reassignment. On the other hand, flexibility of gender roles and freedom to express diverse identities could also result in less perceived need to medical gender reassignment. The clear difference between Finland and the other countries studied here in the overrepresentation of adolescent girls among young people seeking gender reassignment remains unexplained.

The present study has a descriptive design. A strength of the study is that as the gender identity services in all the countries studied are centralized and collaborate closely, we were able to obtain comprehensive figures. The services have been opened in different years in the countries studied and the time series in some countries were therefore shorter than in others. However, we were able to demonstrate the 
strikingly similar developments across countries. Vigorous, multidisciplinary research is needed to understand the phenomenon of increasing treatment-seeking due to gender dysphoria among minors.

Conclusion: A fairly similar pattern of increase in referrals to gender identity services for minors has been seen in the Nordic countries and in the UK. The treatment seeking figures for minors appear greater than for adults. Intensive research is needed to increase the understanding of gender dysphoria / transgender identification in minors and to determine the treatment approaches best serving the interests of minors.

\section{References}

1. American Psychiatric Association. Diagnostic and Statistical Manual of Mental Disorders. 5th ed. Washington, DC: American Psychiatric Press; 2013.

2. World Health Organization. The ICD-10 Classification of Mental and Behavioural Disorders: Clinical Descriptions and Diagnostic Guidelines. Geneva: World Health Organization; 1992.

3. Drescher J, Cohen-Kettenis PT, Reed GM. Gender incongruence of childhood in the ICD-11: controversies, proposal, and rationale. Lancet Psychiatry 2016 Mar;3(3):297-304.

4. World Health Organization, 2018. ICD-11 for Mortality and Morbidity Statistics. https://icd.who.int/browse11/l-m/en (retrieved 27.10.2018)

5. Zucker KJ. Epidemiology of gender dysphoria and transgender identity. Sexual Health 2017:14;404-411. DOI 10.1071/SH17067

6. Collin L, Reisner SL, Tangpricha V, Goodman M. Prevalence of Transgender Depends on the "Case" Definition: A Systematic Review. J Sex Med 2016 Apr;13(4):613-626.

7. Oxford Dictionary. https://en.oxforddictionaries.com/definition/cisgender (referenced November 2018)

8. Gray SAO, Carter AS, Levitt H. A critical review of assumptions about gender variant children in psychological research. Journal of Gay and Lesbian Mental Health 2012;16(1):4-5-30.

9. Ristori J, Steensma TD. Gender dysphoria in childhood. International Review of Psychiatry 2016;28(1):1320.

10. Cohen-Kettenis PT, Klink D. Adolescents with gender dysphoria. Baillieres Best Pract Res Clin Endocrinol Metab 2015 Jun;29(3):485-495.

11. Coleman E, Bockting W, Botzer M, et al. Standards of Care for the Health of Transsexual,Transgender, and Gender Nonconforming People, $7^{\text {th }}$ version. World Professional Association for Transgender Health (WPATH), 2012.

https://www.wpath.org/media/cms/Documents/SOC\%20v7/Standards\%20of\%20Care V7\%20Full\%20Book English.pdf retrieved Jan 2019

12. Colebunders B, Brondeel S, D'ArpaS, et al. An Update on the Surgical Treatment for Transgender Patients. Sex Med Rev 2017: 5(1); 103-109 
13. Staphorsius A, Kreukels B, Cohen-Kettenis PT, et al. Puberty suppression and executive functioning: An fMRI-study in adolescents with gender dysphoria. Psychoneuroendocrinology 2015:56; 190-199

14. Schneider MA, Spritzer PM, Soll B, et al. Brain Maturation, Cognition and Voice Pattern in a Gender Dysphoria Case under Pubertal Suppression. Front Human Neurosci 2017: 11; 528

15. Vlot MC, Klink DT, den Heijer M, et al. Effect of pubertal suppression and cross-sex hormone therapy on bone turnover markers and bone mineral apparent density (BMAD) in transgender adolescents. Bone 2017: 95;11-19

16. Klink D, Caris M, Heijboer A, et al. Bone Mass in Young Adulthood Following Gonadotropin-Releasing Hormone Analog Treatment and Cross-Sex Hormone Treatment in Adolescents With Gender Dysphoria. J Clin Endocrinol Metab 2015: 100 (2) E270-E275, https://doi-org.helios.uta.fi/10.1210/jc.2014-2439

17. Hembree WC, Cohen-Kettenis PT, Gooren L, et al. Endocrine Treatment of Gender-Dysphoric/GenderIncongruent Persons: An Endocrine Society Clinical Practice Guideline. J Clin Endocrinol Metab. 2017; 102(11):3869-3903.

18. Schagen SE, Cohen-Kettenis PT, Delemarre-van de Waal, et al. Efficacy and Safety of GonadotropinReleasing Hormone Agonist Treatment to Suppress Puberty in Gender Dysphoric Adolescents. J Sex Med 2016: 13 (7); 1125-1132

19. Aitken $M$, Steensma TD, Blanchard R, et al. Evidence for an altered sex ratio in clinic-referred adolescents with gender dysphoria. J Sex Med 2015: 12(3):756-763.

20. Wood H, Sasaki S, Bradley SJ, et al. Patterns of referral to a gender identity service for children and adolescents (1976-2011): age, sex ratio, and sexual orientation. J Sex Marital Ther 2013;39(1):1-6.

21. Wiepjes CM, Nota NM, de Blok CJ, et al. The Amsterdam Cohort of Gender Dysphoria Study (19722015): Trends in Prevalence, Treatment, and Regrets. J Sex Med 2018:15:582-590

22. Steensma TD, Cohen-Kettenis PT, Zucker KJ. Evidence for a change in the sex ratio of children referred for gender dysphoria: Data from the Center of Expertise on Gender Dysphoria in Amsterdam (1988-2016) [Letter to the Editor]. J Sex Marital Ther 2018:77;713-715. doi:10.1080/0092623X.2018.1437580.

23. De Graaf N, Giovanardi G, Zitz C, Carmichael P. Sex Ratio in Children and Adolescents Referred to the Gender Identity Development Service in the UK (2009-2016). Archives of Sexual Behavior 2018;47:13011304. doi.org/10.1007/s10508-018-1204-9

24 de Graaf NM, Carmichael P, Steensma TD, Zucker KJ. Evidence for a Change in the Sex Ratio of Children Referred for Gender Dysphoria: Data From the Gender Identity Development Service in London (20002017). J Sex Med 2018;15:1381-1383

25. Kaltiala-Heino R, Bergman H, Työläjärvi M, Frisén L. Gender dysphoria in adolescence: current perspectives. Adolescent Health, Medicine and Therapeutics 2018:9:31-41

26. Danmarks Statistik: https://www.dst.dk/da referenced in 27.10 .2018

27. Tilastokeskus http://pxnet2.stat.fi/PXWeb/pxweb/fi/StatFin/ referenced in 27.10.2018

28. Statistisk Sentralbyrå. https://www.ssb.no/ referenced in 27.10.2018

29. Statistiska Centralbyrån. http://www.scb.se/ referenced in 27.10.2018

30. Office for National Statistics: https://www.ons.gov.uk/ referenced in 27.10.2018 
31. Åhs J, Dhejne C, Magnusson C, et al. Proportion of adults in the general population of Stockholm County who want gender affirming medical treatment. PLoSONE 2018:13(10): e0204606. https://doi.org/10.1371/ journal.pone.0204606

32. Kaltiala-Heino R, Lindberg N. Gender identities in adolescent population: methodological issues and prevalence across age groups. European Psychiatry 2019:55:61-66

33. Mueller SC, De Cuypere G, T'Sjoen G. Transgender Research in the 21st Century: A Selective Critical Review from a Neurocognitive Perspective. Am J Psychiatry 2017;174(12):1155-1162.

34. Marchiano L. Outbreak: On Transgender Teens and Psychic Epidemics. Psychological Perspectives. 2017:60:345-366.

35. Littman L. Rapid-onset gender dysphoria in adolescents and young adults: A study of parental reports. PLOS ONE 13(8): e0202330. https://doi.org/10.1371/journal.pone.0202330

36. McGuire JK, Anderson CR, Toomey RB, Russell ST. School climate for transgender youth: A mixed method investigation of student experiences and school responses. J Youth Adolesc 2010:39(10):11751188.

37. Bos H, Sandfort T. Gender nonconformity, sexual orientation, and Dutch adolescents' relationship with peers. Arch Sex Behav 2015:44(5):1269-1279.

38. de Vries AL, Steensma TD, Cohen-Kettenis PT, ET AL. Poor peer relations predict parent- and selfreported behavioral and emotional problems of adolescents with gender dysphoria: A cross-national, crossclinic comparative analysis. Eur Child Adolesc Psychiatry. 2016:25(6):579-588.

39. Holt V, Skagerberg E, Dunsford M. Young people with features of gender dysphoria: Demographics and associated difficulties. Clin Child Psychol Psychiatry 2016:21(1):108-118.

40. Kaltiala-Heino R, Sumia M, Tyolajarvi M, Lindberg N. Two years of gender identity service for minors: Overrepresentation of natal girls with severe problems in adolescent development. Child Adolesc Psychiatry Ment Health 2015:9:9.

41. de Graaf NN, Cohen-Kettenis PT, Carmichael P, de Vries ALC, Dhondt K, Laridaen J, Pauli D, Ball J, Steensma TD. Psychological functioning in adolescents referred to specialist gender identity clinics across Europe: a clinical comparison study between four clinics. European Child \& Adolescent Psychiatry 2018; 27:909-919. doi.org/10.1007/s00787-017-1098-4

42. Shiffman M, VanderLaan DP, Wood H, Hughes SK, Owen-Anderson A, Lumley MM, Lollis SP, Zucker KJ. Behavioral and emotional problems as a function of peer relationships in adolescents with gender dysphoria: A comparison to clinical and non-clinical controls. Psychology of Sexual Orientation \& Gender Diversity 2016: 3; 27-36.

43. Kroger J. Identity Development: Adolescence Through Adulthood. 2nd ed. Thousand Oaks, CA: Sage Publications; 2007.

44. Kroger J, Martinussen M, Marcia JE. Identity status change during adolescence and young adulthood: A meta-analysis. J Adolesc 2010;33(5):683-698.

45. Moshman D. Adolescent rationality and development. Cognition, morality, and identity. 3rd ed. New York: Psychology Press; 2011 
46. Barbieri D, Franklin P, Janeckova H, et al. Gender Equality Index 2017: Measuring gender equality in the European Union 2005-2015 - Report. https://eige.europa.eu/ retrieved in 27.10.2018 
Figure 1. Referrals to child and adolescent gender identity services 2010-2017 in four Nordic countries

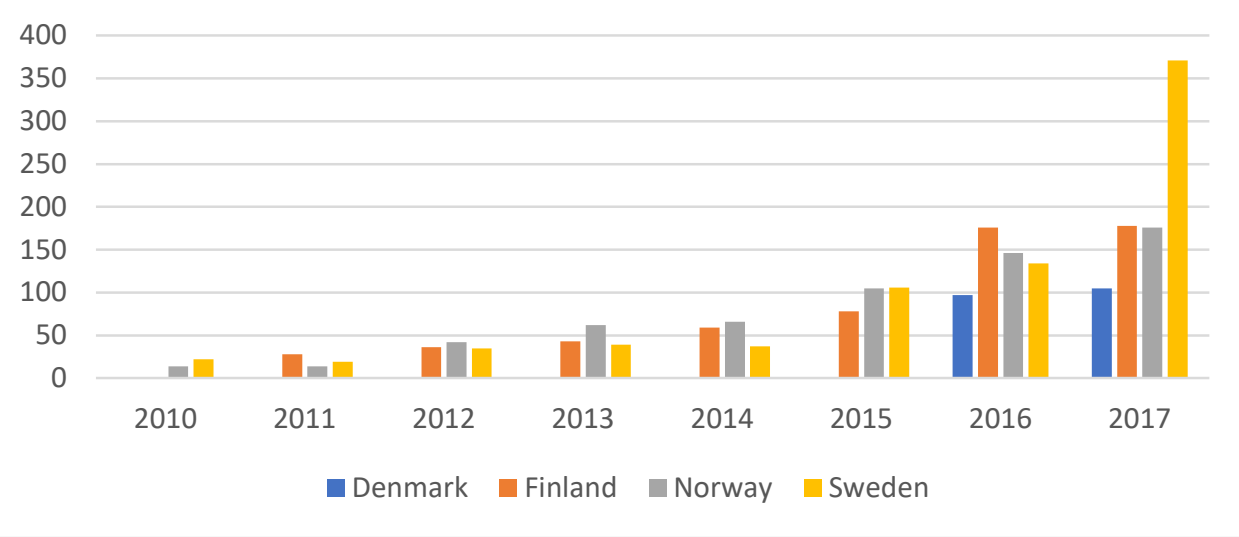




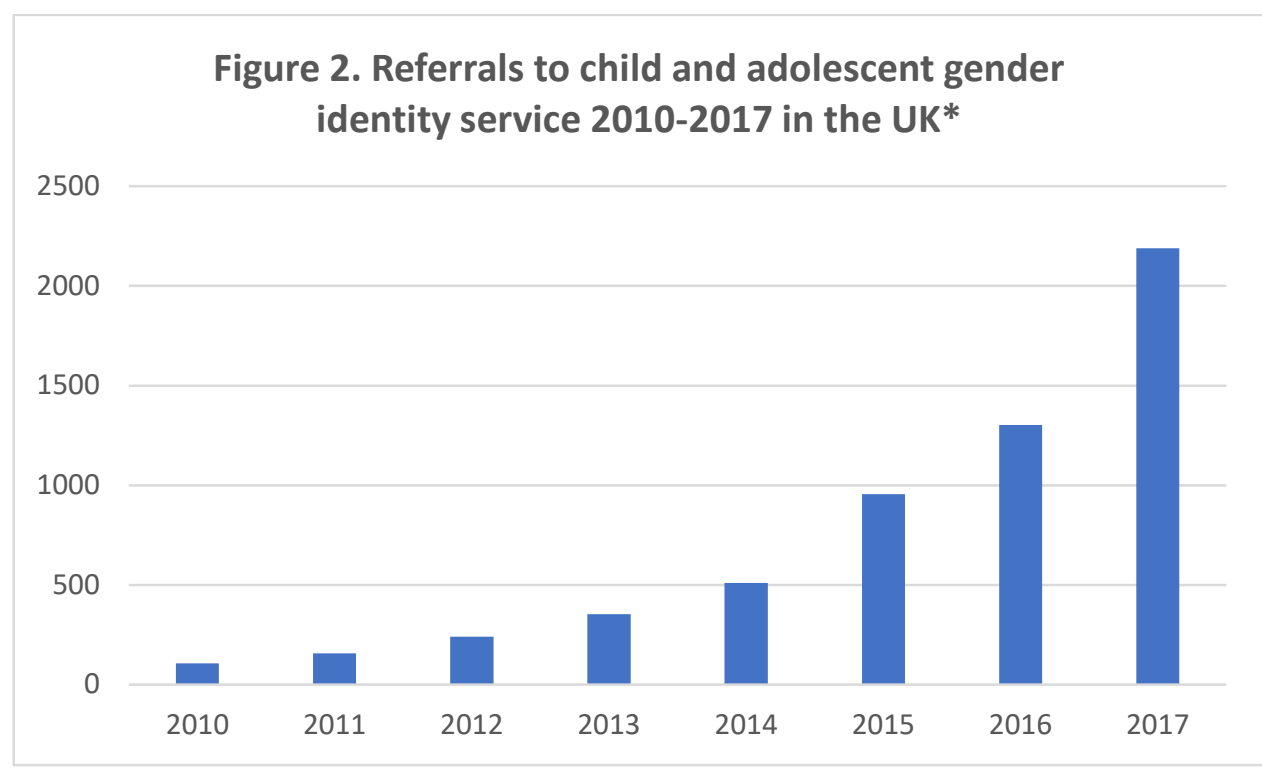

* Notice that the scaling is different from that in Figure 1. 
Figure 3. Development of female:male ratio among children and adolescents referred to gender identity services

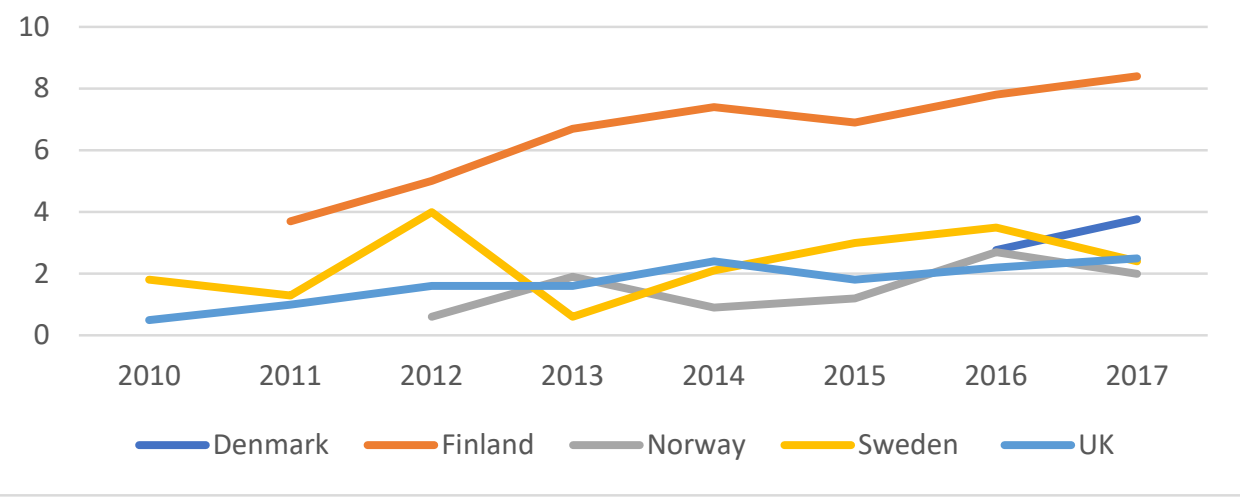


Table 1. Population adjusted numbers of referrals to gender identity services for minors in four Nordic countries and the UK in 2011 and 2017.

\begin{tabular}{|l|l|l|}
\hline & 2011 & 2017 \\
\hline Denmark ${ }^{1}$ & - & $9.0 / 100000(1 / 11000)^{* *}$ \\
\hline Finland & $2.63 / 100000(1 / 38071)^{*}$ & $16.7 / 100000(1 / 10155)$ \\
\hline Norway & $1.24 / 100000(1 / 80643)$ & $15.6 / 100000(1 / 6414)$ \\
\hline Sweden & $0.90 / 100000(1 / 111663)$ & $17.4 / 100000(1 / 5719)$ \\
\hline UK & $1.25 / 100000(1 / 79588)$ & $17.5 / 100000(1 / 5078)$ \\
\hline
\end{tabular}

${ }^{1}$ Service not in operation in 2011

* Finland vs. Norway $p<0.05$; Finland vs Sweden $p<0.001$; Finland vs. the UK $p<0.001$

** Denmark vs. Finland, Denmark vs. Norway, Denmark vs. Sweden, Denmark vs. UK: all $p<0.001$ 
Table 2. Population adjusted numbers of referrals to gender identity services for minors in four Nordic countries and the UK in 2011 and 2017

$\begin{array}{lll} & 2011 & 2017 \\ \text { Denmark* } & - & 9.0 / 100000 \\ \text { Finland } & 2.63 / 100000 & 16.7 / 100000 \\ \text { Norway } & 1.24 / 100000 & 15.6 / 100000 \\ \text { Sweden } & 0.90 / 100000 & 17.4 / 100000 \\ \text { UK } & 1.25 / 100000 & 17.5 / 100000\end{array}$

*Service not in operation in 2011 